\title{
Earth's Precambrian Era as a Common Evolutionary Theme in Two Art Courses at Winona State University
}

\author{
Bruno Borsari • Robin Richardson • \\ Anne Scott Plummer • Mary Coughlan • \\ Jennifer Anderson
}

Published online: 24 January 2008

(C) Springer Science + Business Media, LLC 2008

\begin{abstract}
A multidisciplinary approach to teaching was adopted in two art courses by employing concepts of evolutionary biology with a focus on the Precambrian Era. This knowledge served to help students create original art pieces while learning and applying concepts that are often challenging to non-science majors. This evaluation report shows the efficacy of our teaching methods and will hopefully inspire educators to creatively enhance the teaching of evolution across the curriculum.
\end{abstract}

Keywords Science courses $\cdot$ Precambrian Era $\cdot$ Art courses

\section{Introduction}

A general dislike and lack of appreciation for science courses affects a majority of college students to the point that this attitude often may jeopardize their learning in other subjects and ultimately compromise their academic success. Among the barriers to learning science are the persistent emphasis on factual memorization, rigidity of the curricu-

B. Borsari $(\bowtie) \cdot R$. Richardson

Department of Biology, Winona State University,

215 Pasteur Hall,

Winona, MN 55987, USA

e-mail: BBorsari@winona.edu

A. Scott Plummer $\cdot$ M. Coughlan

Department of Art, Winona State University,

204 Watkins Hall,

Winona, MN 55987, USA

J. Anderson

Department of Geoscience, Winona State University,

114 Pasteur Hall,

Winona, MN 55987, USA lum, and a lack of real world applications, problems which are often perceived by students in a 'traditional' science class (Tobias 1990). Often, these barriers can contribute to a lack of understanding of evolution, its place as a foundation of modern biology, and its applications in other sciences and many other disciplines (Alters and Nelson 2002). This omission undermines the ability of modern science curricula to achieve science literacy in our students and foster an educated society as a whole. As educators, our challenge is thus to make evolution meaningful and relevant to our students so that science becomes less about rote memorization and more about active exploration of the natural world. To see how science could be made relevant to nonscientists, we approached the teaching of science to nonmajors at Winona State University through a multidisciplinary pedagogy during the spring semester 2006.

Our project consisted of an attempt to fuse evolutionary biology with ceramics and printmaking through interdisciplinary instruction from faculty with artistic and scientific backgrounds. The criteria to be measured were accessibility and likeability by students for this new learning opportunity through an assessment of their ceramics and printmaking course to be accomplished at the end of the semester. We thought of considering the early stage of Earth's natural history (Precambrian Era) as a theme to be presented to non-science majors enrolled in these two art classes. An additional incentive that was offered to students in order to enhance more active participation and commitment to course work was the opportunity to have their work selected to be permanently displayed in the newly constructed Science Building (Science Laboratory Center).

We thought that the possibility of creating original art pieces and having "art on display" to present the Earth's natural history may motivate students' learning through a direct application of knowledge they have gained in course 
work thus legitimize the relevance of the learning process. Hedeen (1997) was successful in enhancing students' interests for Earth's evolutionary history by developing an interpretive trail up the stairs of a college campus. We conceded that our endeavor could have had similar potential also for art students with appropriate adaptations from Hedeen's initial experience. Our proposed method of instruction was supported also by Sinclair (2003), who pointed out that appropriate teaching methods contribute to art majors' appreciation of the living world, and others (Kelley et al. 2001; McCormack and Smucker 1982) who substantiated the idea of a multidisciplinary approach to education as an effective strategy to foster students' engagement, learning, and a better appreciation for the curriculum. In agreement with these creative pedagogies, we remained convinced that such an exposure would have inspired students to create effective art pieces that could speak to all students interested in learning more about the evolutionary history of Earth.

Additionally, an emerging interest in displaying science is not only an opportunity to enhance specific curricula but also to use space creatively for the purpose of educating building users and visitors about science and scientific inquiry (Narum 2004).

In accordance with this approach, we wanted to add creative art pieces (among real specimens) to the collection already on display to demonstrate active learning while celebrating non-science majors for their effort to communicate scientific concepts to the community of learners at Winona State University.

Therefore, the main purpose of our project was to make the theory of evolution more accessible and likeable to students by having them explore a science concept from a different perspective than that in which science is traditionally taught, namely through artistic exploration. At the end of the term, we evaluated the proposed learning experience to substantiate the feasibility of our endeavor. As the project progressed, data were taken at different times during the semester, with an expectation that the utility of this method would be recognized and such collaborations among faculty and across departments could be supported again in the future.

\section{Methods}

The authors formed a multidisciplinary team of art and science professors that had previously indicated an interest in engaging students who were majoring in a variety of curricula (primarily in the fine arts, but potentially in any field) in innovative and unique learning experiences. At the onset of the spring semester 2006 the two art classes met in a science laboratory where the three science professors engaged their audience in a 30-min presentation about the early natural history of Earth, from geological and biological perspectives. After the presentation, students and professors explored rocks and stromatolites from the Precambrian and engaged in discussions about art, science, and the early history of Earth (Figs. 1a and b).

After this initial meeting, students were guided by all the instructors throughout the term in a multidisciplinary and collaborative learning process to create original art pieces. The science professors each visited the art studios once a month for about $1 \mathrm{~h}$ when the art courses were in session, for a total of nine visits to each class, throughout the semester. The purpose of these visits consisted of monitoring students' work through a review and critique of preliminary sketches (initially), small scale models (in the ceramics course), and progression toward the creation of their art piece in the presence of their art instructor. The visits allowed further discussion and clarification of concepts and issues about the theme under study in what we thought was the most comfortable learning environment for art students: their studios. The Precambrian Era was
Fig. 1 a and b Students examine fossils (stromatolites) and consult with Dr. Anderson
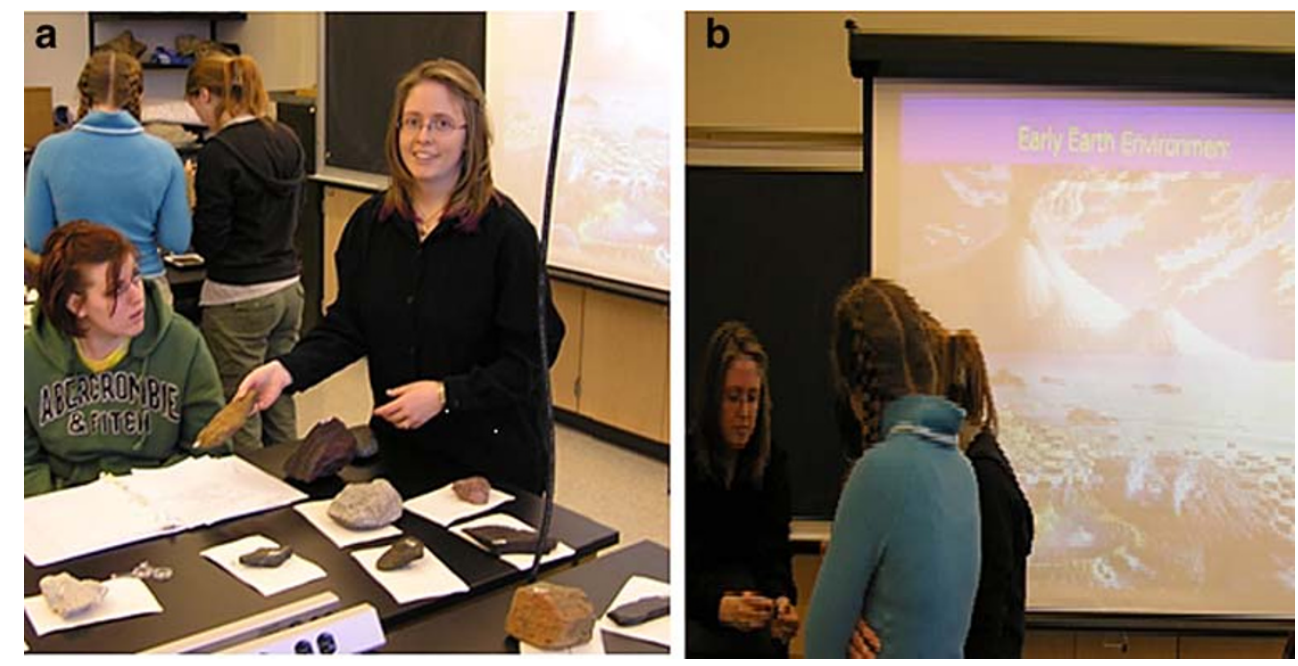
selected as a common theme to frame the project within a typical one-semester period and to avoid overwhelming students with excessive information.

\section{The Instructional Process}

The science professors contributed to this endeavor by producing a PowerPoint presentation, which they delivered to students during the first week of class of the spring semester. The brief lecture on the Precambrian Era lasted about $30 \mathrm{~min}$ and served the purpose of introducing students to the scientific concepts and issues of the selected theme that they were going to employ for creating their individual art pieces. This was visually rich and included a video clip of a high speed impact experiment such as those performed at the NASA Ames Vertical Gun Range (Gault and Wedekind 1978; Anderson et al. 2003) to simulate in slow motion the outcome of asteroid collisions, as might have occurred in the early stage development of planet Earth.

The art professors allowed for flexibility in their curriculum to accommodate the proposed theme during the entire semester and guided students in their creative effort.

Each student considered an evolutionary concept or event from those presented and did further research with the intent of creating an original art piece that visually interpreted that concept or event. Numerous sketches and even small scale models (in the ceramics course) were produced before the creation of the actual art pieces (Figs. 2 and 3).

The PowerPoint presentation remained posted online for further review and consideration throughout the semester. The three science professors remained available to students

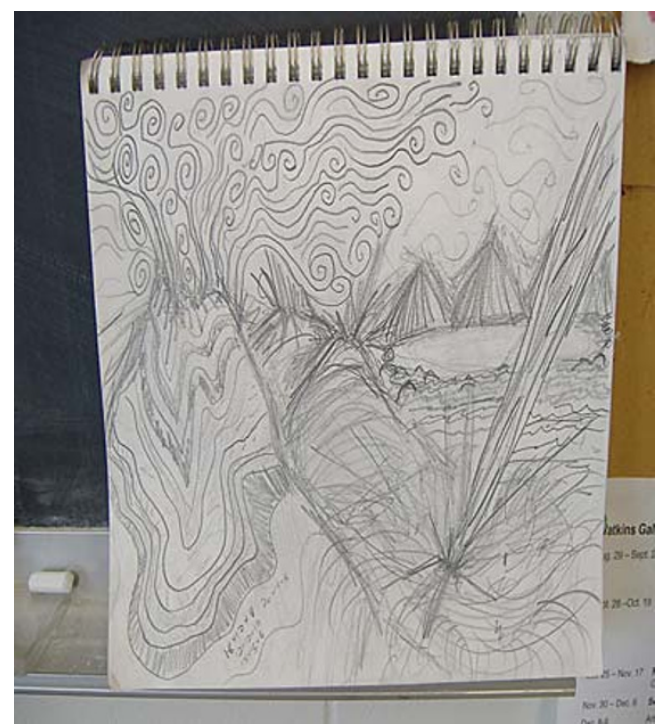

Fig. 2 Student's sketch book from the printmaking course illustrating volcanism and meteor impacts during the Precambrian Era

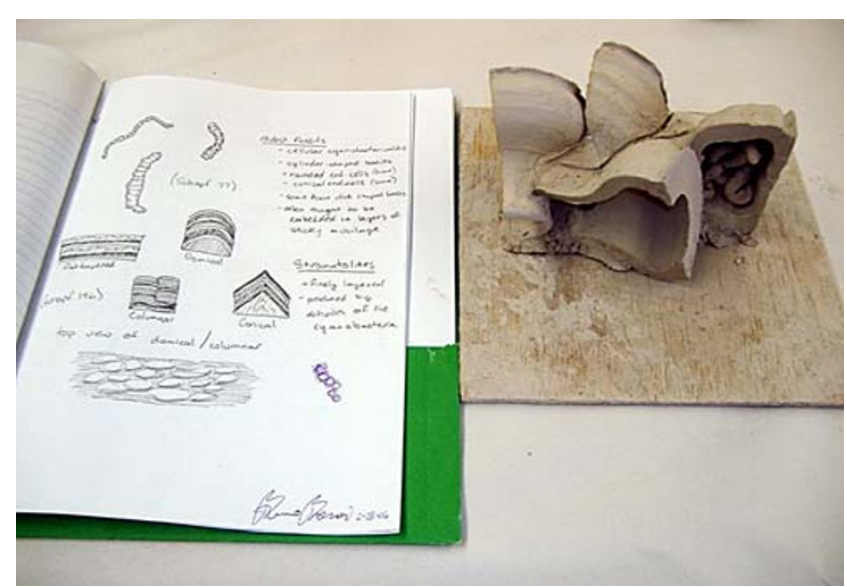

Fig. 3 Student's sketch book with annotations and small-scale model of the first colonial organisms of the Precambrian Era (stromatolites)

for individual or small group consultations, in addition to the monthly visits from each one of them to the art studios (Fig. 4).

After the term assignments were completed at the end of the semester, projects were selected by the professors (three pieces from each course group) to be displayed permanently in the atrium of the Science Laboratory Center with appropriate signage crediting the student artists (Figs. 5 and 6).

\section{Data Collection}

At the end of the semester, students were surveyed with a purposefully designed assessment instrument (Fig. 7).

The survey proposed 18 questions. Sixteen of these asked students to select a descriptor phrase in a five-point Likert scale, whereas 2 questions were open-ended. The latter served to include qualitative data to the survey responses as recommended by Patton (1990) as a viable approach used in evaluation studies. The 16 survey questions were designed to collect raw, quantitative data to

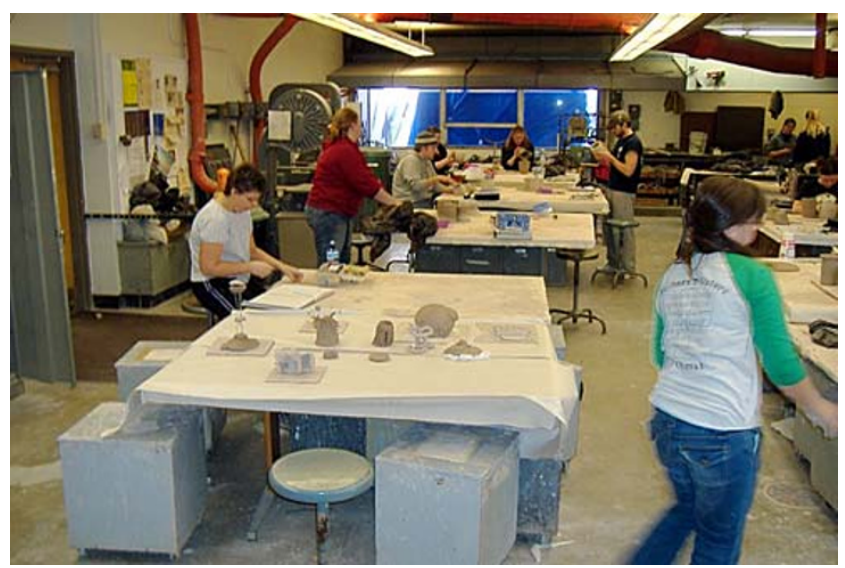

Fig. 4 Students at work in the ceramics studio. Several models of art pieces are on display in the forefront 


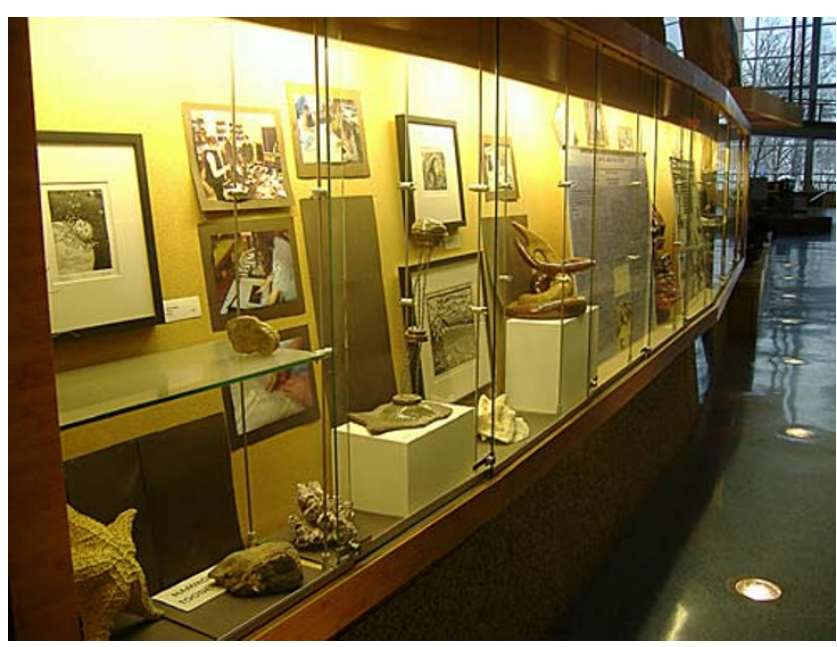

Fig. 5 Selected art pieces (print and ceramic) illustrating the Precambrian Era on display in the Science Laboratory Center at Winona State University. The three prints are framed, two ceramics are on the white pedestals, and the third one is in the back, leaning against the wall, after the poster (Fig. 6)

evaluate the art courses from five main attribute categories (project goals and outcomes, assessment, independent thinking, learning environment, overall evaluation).

The two open-ended questions allowed respondents to include remarks that were not presented by the survey. Additional qualitative data were provided by the professors' observation notes that were taken during consultations with students and visits to the art studios. According to Popham (1993), evaluation studies need to consider a combination of qualitative and quantitative data to enhance the validity of any assessment endeavor. Researchers can become valuable research subjects if their inclusion in the research design is not obstructive (Patton 1990) and considers the attenuation of potential investigators' bias (Glesne 1999). To this end, the professors attempted to maintain a neutral

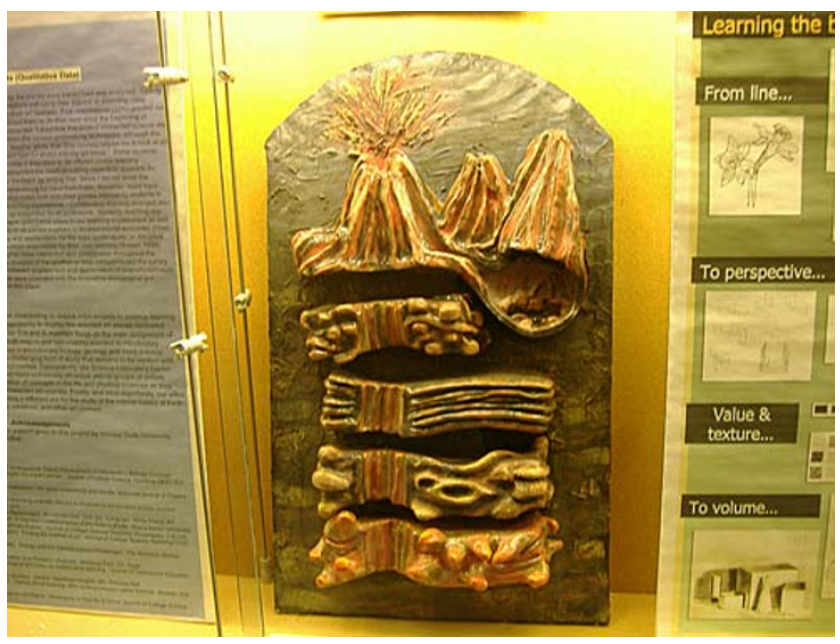

Fig. 6 One of the selected ceramic pieces illustrating volcanism during the Precambrian Era stance during conferences and visits with students by simply asking them to describe their work and by remaining available to answer their questions or concerns, without leading the conversation but simply listening to students and responding to their inquiries.

\section{Results and Discussion}

Data were collected in May to evaluate the art courses and provide an indication of the worth of our multidisciplinary, instructional methodology for possible future expansions of the same, beyond the one-semester study. The purposefully designed survey was administered to students, and observation notes that the professors wrote added more qualitative data for the analysis. In this manner, a triangulation of the results enhanced the trustworthiness of this evaluation study (Popham 1993).

\section{Survey Results}

Two groups of art students participated in this project: a ceramic class $(n=15)$ and a print making class $(n=12)$. The raw percentage scores of students' responses from the print making class and the ceramics class are presented below (Fig. 8).

In addition to this, a correlation of the mean values for each descriptor phrase on a five-point Likert scale revealed that all the five main attribute categories as proposed by the instrument were significantly related, $r=+0.985, n=5, p<$ 0.01, two tails, for both the print making and the ceramics course. Therefore, the analysis of the survey data suggests students' appreciation for their art course, inspired by the Precambrian Era as a common theme of study to learn evolutionary theory.

The printmaking students were primarily freshmen $(92 \%)$ in their second semester of studies at the university, whereas the ceramics course had only $6 \%$ of these in the whole class. Freshmen at Winona State University are often first-generation college students and their reluctance or difficulty to seek more assistance from the science professors, as they were not their main instructors, remains challenging to explain. More likely, these students were still completing their 'adaptation phase' to college life, and for this reason, they might have chosen to limit their interaction with the science professors only during the formal visitations of these to the art studios.

\section{Qualitative Data}

The answers of the two open-ended questions posed by the survey were transcribed and analyzed. Twenty-two of the twenty-seven art students answered the questions indicating 
L21 Art Project Section \#: __ Date:

This survey is part of an effort to evaluate your learning experience in this Art course, this semester. The best data that we can gather about the art project come from you. The information that you provide on this survey can help us verify the validity of the course and make it more effective in the future. Because your responses on this survey are so important, please answer each question carefully and thoughtfully. Please indicate how much you agree or disagree with each statement by marking one choice (a,b,c,d,e) on your Scantron: PEASE DO NOT IDENTIFY YOURSELF.

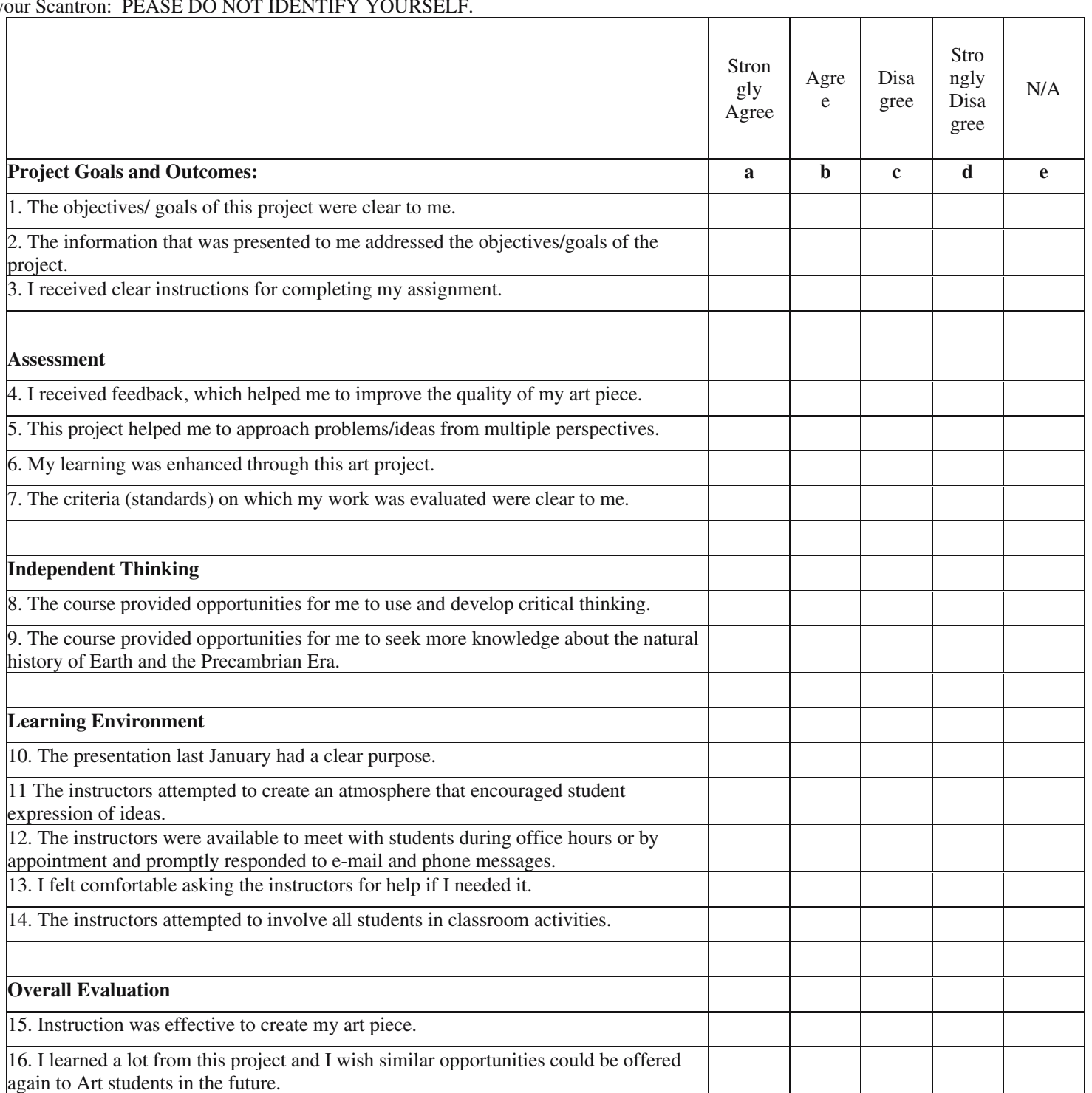

OPEN-ENDED QUESTIONS. (Please answer on the back of this form)

1) Please explain the extent to which you fulfilled your responsibilities as a student (e.g. keeping up with the work, carefully planning and executing your work, preparing for participating in class, attending class).

2) Please state what you think are the strengths of this course project and why you think so. Also how do you think the project may be improved?

THANK YOU FOR COMPLETING THIS SURVEY.

Fig. 7 Assessment instrument

their interest in attending class because of the clear objectives and expectations from their art courses. Five respondents $(22 \%)$ pointed out that an opportunity to have their work on display motivated them to do their best since the beginning of course work. One student in the ceramics course commented "I liked how this project connected science and the arts." A second one added "It was interesting to learn the various printmaking techniques, although the expectations were very high for being an intro class." Another wrote that "[the course] helped me to look 


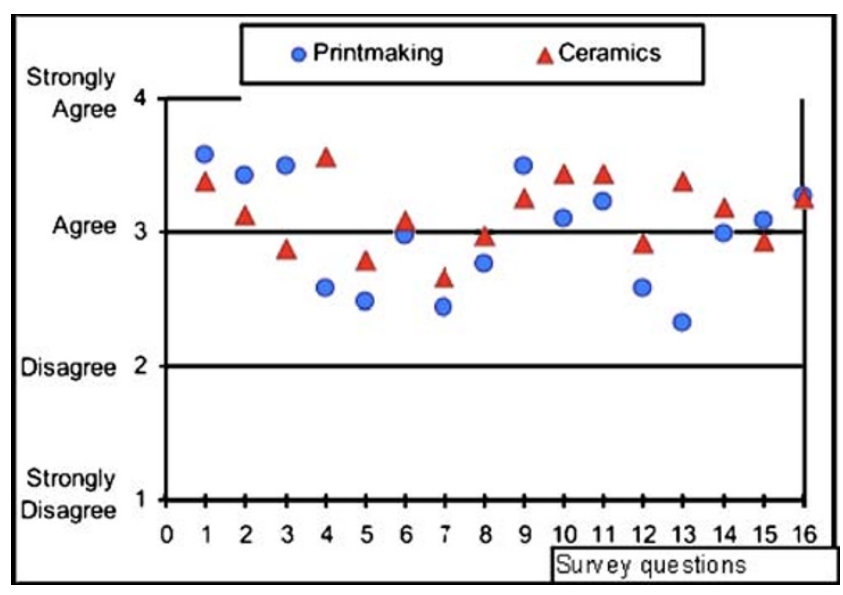

Fig. 8 Survey responses from the print making and ceramics classes

at art from a different aspect. I liked to incorporate a different field [of study] with my art minor." Some students (31\%) did not have suggestions to improve these courses if they were to be offered similar learning opportunities in the future. Two students $(9 \%)$ recommended the need of making more time available for courses of this kind. One suggested more instructor feedback by writing that "Since I did not know the science instructors personally, I did not feel comfortable asking for input from them. However, more input would have been nice."

The art professors' observation notes both indicated greater interest by students in the subject being taught as compared to previous teaching experiences. Cooperative learning emerged also as a tangible outcome of this semester experience as suggested by all professors. Students teaching one another as presented previously by Crouch and Mazur (2001) took place in our learning environment as well. Cooperation among learners is extremely beneficial to all parties involved in an educational encounter (Pinet 1995) and it was gratifying to observe that learning and appreciation for the topic or discipline under study can truly be enhanced by letting students become more responsible for their own learning (Borsari 1999). The two art professors noted also that besides higher class interaction and participation throughout the semester, there was less class absenteeism because of the unique focus geared towards the selection of students' work to be on permanent display. One professor was appreciative of this experience for having had an opportunity to take her students into science building for the first time, when they attended the initial presentation about the Precambrian Era, thus exposing them to a different learning environment that normally may be perceived as intimidating by non-science majors. The science professors unanimously indicated their desire to continue teaching in these and similar didactic approaches as they saw a viable link strengthening science and art, through this project. As an outcome of this initial experience, one science professor developed and taught an interdisciplinary course with a colleague in the Theatre Department to connect dance and astronomy the following semester. One of the biology professors has developed a curriculum on sustainability with a professor from the English Department to explore concepts of conservation biology and ecology through literature and field studies.

The analysis of the qualitative data complemented the survey results and led to similar conclusions about an increased engagement and appreciation of scientific concepts gained by students in the art courses, when these were proposed with the innovative pedagogical and instructional emphasis that has been illustrated in this paper.

\section{Conclusion}

A variety of teaching strategies exist for enhancing learning evolution (Jungck et al. 2005) and the sciences, and for engaging students in meaningful educational experiences (McCormack and Smucker 1982; Tobias 1990; Crouch and Mazur 2001). Convergent thinking and the data-driven approaches to explaining natural phenomena typical of scientific thinking (Prince and Felder 2007) should not alienate the more subjective and divergent type of thinking of other students, as we remain convinced that all students can understand science if they are offered appropriate educational opportunities. The typical one-semester timeframe did not allow us to measure quantitatively the knowledge gained by students in the theme that was proposed, as we could have done through a needs assessment. Despite this limitation, however, this project served several purposes besides contributing to reduce impediments to science learning as described by DeCaprariis (1997) and evolution. The opportunity to display the selected art pieces motivated students to learn more about the Precambrian Era and to maintain focus on the main assignment of their art course. Hopefully, this educational experience will help them to maintain momentum toward learning science if more professors will embrace similar collaborative and multidisciplinary approaches in their teaching. Reducing anxiety and apprehension among students (both majors and non-majors) enrolled in introductory science courses and encouraging their interest in evolutionary biology, geology, and more science-related courses and curricula constitutes a challenging field of study that remains to be investigated with more research in collaborative teaching approaches. In the meantime, our Science Laboratory Center (SLC) has become more esthetically attractive to the campus community and also to groups of visitors (Narum 2004; Hedeen 1997), through a visual interpretation of concepts in the life and physical sciences as they were interpreted by students enrolled in 
these two art courses. Finally, and most importantly, our effort may continue in the near future by proposing a different Era for the study of the natural history of Earth to new students enrolling in print making, ceramics, and more art courses.

Acknowledgement The authors are grateful for the financial support given to this project by Winona State University, Learning for the twenty-first century (L21) initiative.

\section{References}

Alters BJ, Nelson CE. Teaching evolution in higher education. Evolution. 2002;56(10):1891-901.

Anderson JLB, Schultz PH, Heineck JT. Asymmetry of ejecta flow during oblique impacts using three-dimensional particle image velocimetry. J Geophys Res. 2003;108(E8):5094. DOI 10.1029/ 2003JE002075.

Borsari B. A practical application of andragogical theory assumptions in introductory biology courses. adopting an educational paradigm that targets the adult learner. J Coll Sci Teach 1999;28(5):311-4.

Crouch $\mathrm{CH}$, Mazur E. Peer instruction: ten years experience and results. Am J Phys. 2001;69:970-7.

DeCaprariis PP. Impediments to providing scientific literacy to students in introductory survey courses. J Geosci Educ. 1997;45:207-10.

Gault DE, Wedekind A. Experimental studies of oblique impact. Proceedings of the 9th. Lunar Planetary Science Conference $1978 ; 3843-75$.
Glesne C. Becoming qualitative researchers: an introduction. 2nd ed. White Plains, NY: Longman; 1999.

Hedeen SE. Evolutionary steps. a stairway-created display of the history of life. How a Xavier University biology class plots earth's major evolutionary events. J Coll Sci Teach 1997;27:119 20. November.

Jungck JR, Kiser S, Stanley E. Exploratory evolution education: engaging students in investigating evolutionary processes, products and principles. In: Cracraft J, Bybee RW editors. Evolutionary science and society: educating a new generation.Colorado Springs, CO: BSCS; 2005. p. 125-36.

Kelley C, Jordon A, Roberts C. Finding the science in art. J Coll Sci Teach. 2001;31(3):162-5.

McCormack AJ, Smucker T. Biology and art: interdisciplinary challenges. Am Biol Teach. 1982;44(2):112-5.

Narum JL. Science spaces for students of the 21 st century. Change 2004;36:8-21. Sept./Oct.

Patton MQ. Qualitative evaluation and research methods. Newbury Park, CA: Sage; 1990.

Pinet PR. Rediscovering geological principles by collaborative learning. J Geosci Educ. 1995;43:371-6.

Popham JW. Educational evaluation. 3rd ed. Needham Heights, MA: Prentice Hall; 1993.

Prince M, Felder R. The many facets of inductive teaching and learning. J Coll Sci Teach. 2007;36(5):14-20.

Sinclair C. A biology course for art majors. Developing an eye for science. J Coll Sci Teach 2003;43:22-6.

Tobias S. They're not dumb, they're different: stalking the second tier. Tucson, AZ: Research Corporation; 1990. 